\title{
Cloud FEA of hot stamping processes using a software agnostic platform
}

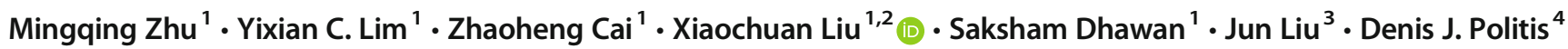

Received: 27 August 2020 / Accepted: 15 December 2020 / Published online: 18 January 2021

(C) The Author(s) 2021

\begin{abstract}
Finite element analysis (FEA) of a hot stamping process demands the implementation of accurate material properties and boundary conditions to precisely predict and evaluate the post-form quality of a component. A software agnostic platform was developed to provide cloud FEA of a hot stamping process in three stages, namely, pre-FE modelling, FE simulation and post-FE evaluation. When the desired materials and process window were uploaded on the platform, the flow stress, material properties, interfacial heat transfer coefficient (IHTC) and friction coefficient were predicted by the model-driven functional modules and then generated in the form of compatible packages that could be implemented into the desired FE software. Subsequently, the FE simulation was performed either locally or remotely on the developed platform. When the simulated evolutionary thermomechanical characteristics of the formed component were uploaded, the formability, quenching efficiency and postform strength could be predicted and then demonstrated on a dedicated visualiser on the developed platform. Cloud FEA of two different hot stamping technologies was conducted to demonstrate the function of the developed platform, showing an error of less than $10 \%$.
\end{abstract}

Keywords Cloud FEA $\cdot$ Hot stamping $\cdot$ Model-driven functional module $\cdot$ Aluminium alloy

\section{Introduction}

Finite element analysis (FEA) software is capable of providing solutions for metal forming processes and optimising the process window without considerable physical efforts [1-3]. In recent years, hot stamping technology has been developed as a novel metal forming process to manufacture complexshaped panel components. Solution Heat treatment, cold-die Forming and in-die Quenching (HFQ) is one such hot

Mingqing Zhu and Yixian C. Lim are joint first authors.

Xiaochuan Liu

liuxiaochuan2020@xjtu.edu.cn

1 Department of Mechanical Engineering, Imperial College London, London SW7 2AZ, UK

2 School of Mechanical Engineering, Xi'an Jiaotong University, Xi'an 710049, China

3 Advanced Forming Research Centre, University of Strathclyde, Glasgow PA4 9LJ, UK

4 Department of Mechanical and Manufacturing Engineering, University of Cyprus, 20537 Nicosia, Cyprus stamping technology for aluminium alloys, in which a blank is first heated to its solution heat treatment (SHT) temperature with a period of soaking time and then deformed and simultaneously quenched by cold dies. Artificial ageing is conducted to achieve a high post-form strength of the formed component. It is beneficial for improving the formability of the material and reducing the springback of the formed component [4-6]. Fast light Alloys Stamping Technology (FAST) is another promising process, involving heating a blank at an ultrafast rate to elevated temperature and immediate quenching in cold dies without any soaking, as shown in Fig. 1. Instead of the lengthy artificial ageing process, the post-form strength of the formed component could be recovered in heat treatment after assembly, such as paint bake cycles, thereby dramatically reducing the production time [7-9]. In addition to aluminium alloys, high strength steels and titanium alloys could also be formed by hot stamping processes developed by Mori et al. $[10,11]$ and Kopec et al. [12], respectively.

FE simulation of hot stamping processes featuring the complex nature of thermal and mechanical fields requires the implementation of accurate material properties and boundary conditions, such as the flow stress dependent on the temperature and strain rate [13], the interfacial heat transfer coefficient 
Fig. 1 Schematic diagrams of the HFQ and FAST forming processes

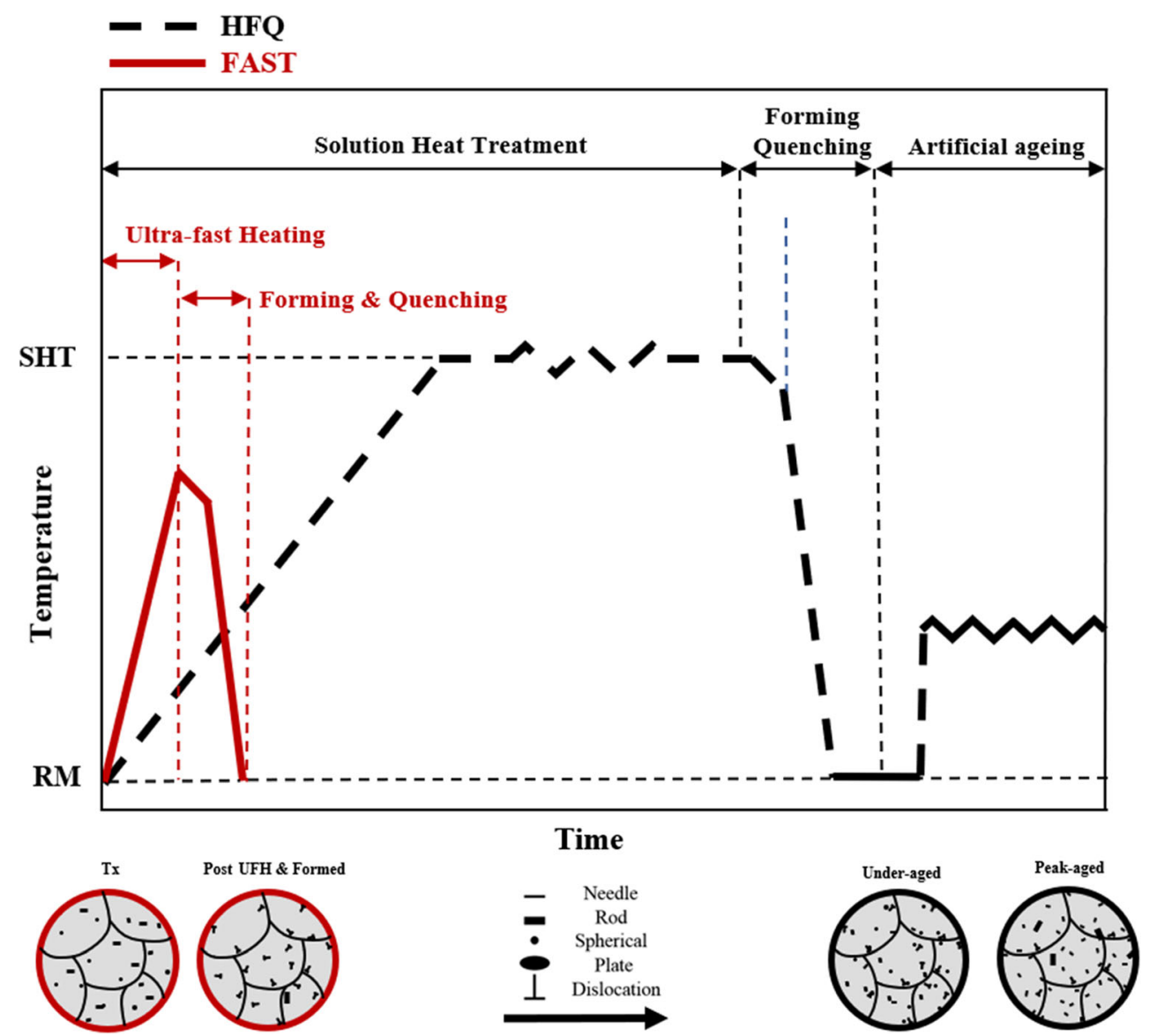

[14] and friction coefficient [15] dependent on the temperature, contact pressure, tool material, lubricant and coating. Subsequently, the simulated results, such as stress, strain and thinning, are used to preliminarily evaluate the quality of the formed components. However, under the complex hot stamping conditions, the failure prediction of the formed components could not be simply determined by the strain and thinning, but evaluated by the forming limit as a comprehensive result of temperature, strain rate and loading path [16]. In addition, the critical quenching rate has to be met to avoid the intersection between the temperature evolutions and continuous cooling precipitation (CCP) diagram of the material to achieve the desired microstructure and post-form strength [7, 17]. Those advanced evaluation criteria of the formed components essential to the hot stamping processes could be computed by post-processing the simulated results in the FE software or user-defined subroutines [18-20]. Therefore, the implementation of accurate material properties and boundary conditions as well as the computation of the advanced evaluation criterion are critical to the FEA of hot stamping processes $[21,22]$.

In the present research, a software agnostic platform was developed to provide cloud FEA of hot stamping processes as well as solutions for specific demands by operating modeldriven functional modules, which could be classified into three main categories, namely, pre-FE modelling, cloud FE simulation and post-FE evaluation. After providing the process window and materials involved in a desired hot stamping process, the functional modules of pre-FE modelling were operated to generate the material properties and boundary conditions, which could be implemented in either local or cloud FE simulation of the hot stamping process. After providing the simulated results, the functional modules of the post-FE evaluation were operated to generate the advanced evaluation criterion of the formed component, such as formability, quenching efficiency and post-form strength. In order to demonstrate the function and accuracy of the developed platform, cloud FEA of hot stamping of a 6082 aluminium alloy was performed and then experimentally verified.

\section{Cloud FEA of hot stamping processes}

\subsection{Pre-FE modelling}

Figure 2 shows the flow chart of cloud FEA of a hot stamping process in the developed platform. The model-driven functional modules of pre-FE modelling were operated accounting for the desired process window and materials. Two different processing windows were used in the present research. First, 
Materials \& Process window

Pre-FE modelling

Flow Stress

IHTC Mate

Tribo Mate

Model-driven

Model-driven

Model-driven

$$
\begin{gathered}
\dot{\varepsilon}_{p}=\left(\frac{\bar{\sigma}-R-k}{K}\right)^{n_{1}} \\
\dot{\bar{\rho}}=A(1-\bar{\rho}) \dot{\varepsilon}_{p}-C \bar{\rho}^{n_{2}} \\
\dot{R}=0.5 B \bar{\rho}^{-0.5} \dot{\bar{\rho}} \\
\bar{\sigma}=E\left(\varepsilon_{T}-\varepsilon_{p}\right) \\
K=K_{0} \exp \left(\frac{Q_{K}}{R T}\right) \\
k=k_{0} \exp \left(\frac{Q_{k}}{R T}\right)
\end{gathered}
$$

$$
\begin{aligned}
& n_{1}=n_{0} \exp \left(\frac{Q_{n}}{R T}\right) \\
& B=B_{0} \exp \left(\frac{Q_{B}}{R T}\right) \\
& A=A_{0} \exp \left(\frac{Q_{A}}{R T}\right) \\
& C=C_{0} \exp \left(\frac{Q_{C}}{R T}\right) \\
& E=E_{0} \exp \left(\frac{Q_{E}}{R T}\right)
\end{aligned}
$$$$
h=h_{a}+h_{s}+h_{c}+h_{t}(t)
$$$$
h_{s}=a_{l} \varphi(T) \frac{K_{s t}}{R_{s t}} N_{p}
$$$$
h_{l}(t)=\omega \frac{K_{s i t} N_{\delta}(t)}{R_{s t}}
$$$$
\alpha_{l}=m \ln (l)+n
$$$$
N_{\delta}(t)=1-\exp \left[-\theta \delta_{i}(t)\right]
$$$$
\kappa_{s t}=\frac{2}{k_{s}^{-1}+k_{t}^{-1}}
$$$$
\varphi(T)=\varphi_{0} \exp \left(\frac{Q_{\varphi}}{R T}\right)
$$$$
\sigma_{\nu}(T)=\sigma_{0} \exp \left(\frac{Q_{a}}{R T}\right)
$$$$
R_{s t}=\sqrt{R_{\mathrm{s}}{ }^{2}+R_{t}^{2}}
$$

$N_{p}=1-\exp \left[-\gamma \frac{P}{\sigma_{U}(T)}\right]$

$h_{c}=\beta \frac{k_{s} \ln \left(\frac{k_{c}}{k_{t}}\right)}{\Lambda} \delta_{c} N_{P}$

$$
\mu=(1-\beta) \mu_{L}+\beta \mu_{d}
$$

$\beta=\exp \left[-\left(\lambda_{l} h(t)\right)^{\lambda 2}\right]$

$K_{s t t}=\frac{3}{k_{s}^{-1}+k_{i}^{-1}+k_{\ell}^{-1}}$

$(0)=A h(t)+\sqrt{A} \int_{0}^{t} f(P, \eta) h(t) v^{\kappa_{1}} d t$

Material card

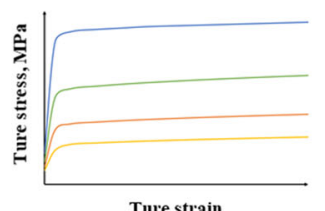

Ture strain
IHTC package

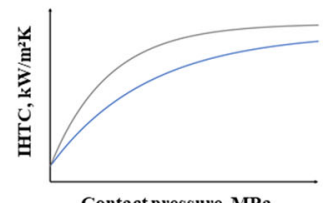

Contact pressure, MPa

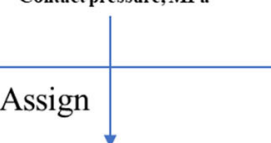

$\dot{h}(t)=-\left(c P^{\kappa_{1}} v^{\kappa_{2}} t\right)$

$h(t)=h(0) \exp \left[-c P^{\kappa_{1}} v^{\kappa_{2}} t\right]$

FE simulation

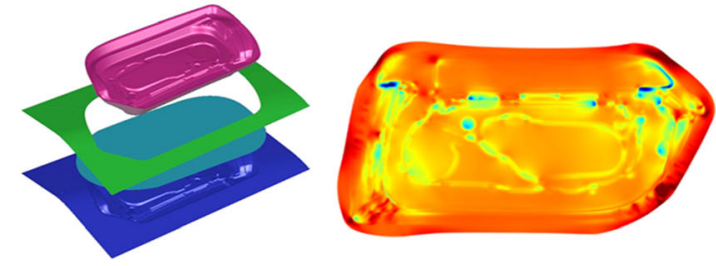

Evolutionary thermo-mechanical characteristics

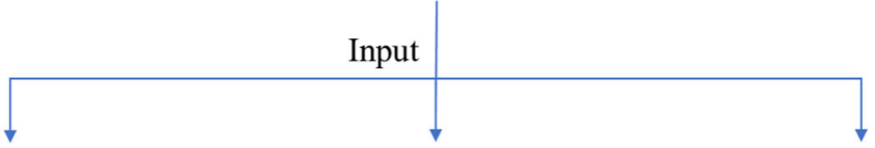

Post-FE evaluation

$$
\begin{gathered}
\text { Model-driven } \\
\varepsilon_{2 A}=\varepsilon_{2 B} \quad \sigma_{1 A}=f \sigma_{1 B} \\
f=\frac{t_{B}}{t_{A}} \quad \frac{d \varepsilon_{3 B}}{d \varepsilon_{3 A}} \geq 10 \\
f=f_{0} \exp \left(\varepsilon_{3 b}-\varepsilon_{3 a}\right) \\
R_{2} \sigma_{11 a}^{l}+R_{1} \sigma_{22 a}^{l}+R_{1} R_{2}\left(\sigma_{11 a}-\sigma_{22 a}\right)^{l}=R_{2}\left(R_{1}+1\right) \bar{\sigma}_{a}^{l} \\
R_{2} \sigma_{11 b}^{l}+R_{1} \sigma_{22 b}^{l}+R_{1} R_{2}\left(\sigma_{11 b}-\sigma_{22 b}\right)^{l}=R_{2}\left(R_{1}+1\right) \bar{\sigma}_{b}^{l}
\end{gathered}
$$

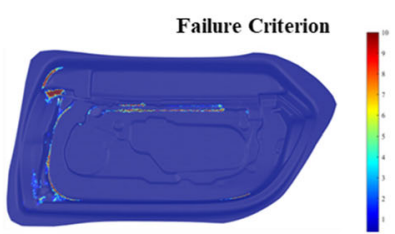

Fig. 2 Flow chart of cloud FEA of a hot stamping process
Quenching efficiency

Mechanism-based

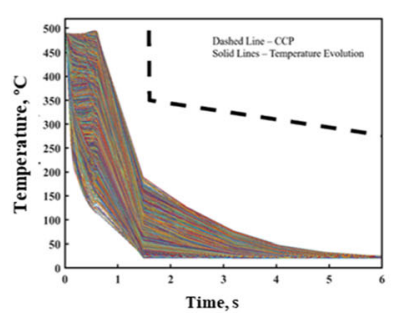

Quenching Efficiency

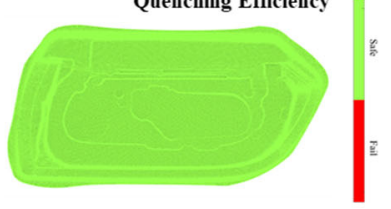

\section{Post-form strength}

Model-driven

$$
\begin{array}{cc}
\bar{\rho}=1-\frac{\rho_{i}}{\rho} & \sigma_{s h}=C_{2} f_{t}^{0.5} r^{0.5} \\
\dot{\bar{\rho}}=A(1-\rho) \dot{\varepsilon}_{p}-C \bar{\rho}^{n_{2}} & \sigma_{b y}=C_{3} f_{t}^{0.5} r^{-1} \\
\sigma_{y}=\sigma_{d i s}+\sigma_{s s}+\sigma_{i}+\sigma_{p p t} & \sigma_{s s}=C_{4} C_{t}^{2 / 3} \\
\sigma_{p p t}=\frac{\sigma_{b y} \sigma_{s h}}{\sigma_{b y}+\sigma_{s h}} & \sigma_{d i s}=A_{d} \bar{\rho}^{0.5}
\end{array}
$$

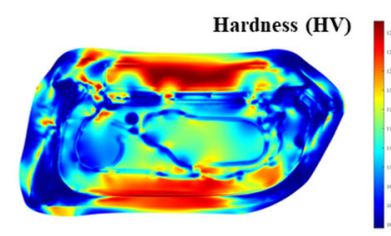


an AA6082 blank was heated to $300^{\circ} \mathrm{C}$ at a fast heating rate of $50{ }^{\circ} \mathrm{C} / \mathrm{s}$. Without any soaking or pronounced temperature drop, it was immediately deformed by cold tools made from a P20 tool steel and lubricated by a graphite-based lubricant, at a stamping speed of $250 \mathrm{~mm} / \mathrm{s}$. Second, an AA6082 blank was heated to $535{ }^{\circ} \mathrm{C}$ and then soaked for a period in a furnace. Subsequently, the hot blank was transferred to a press machine and deformed by lubricated cold P20 tools at a forming temperature of $490{ }^{\circ} \mathrm{C}$ and a stamping speed of $250 \mathrm{~mm} / \mathrm{s}$.

\subsubsection{Flow stress and material card of AA6082}

The functional module, flow stress, was operated to predict the stress-strain curves of the blank material AA6082 at a range of temperatures and strain rates to generate a look-up table or package compatible to the FE software, as shown in Fig. 3. Alternatively, the stress-strain curves could be acquired by performing the functional module, Material card. Meanwhile, the material properties of both the blank and tool materials shown in Table 1 were also contained in their material cards. Both functional modules were driven by the viscoplastic constitutive equations, as shown in Eqs. (1), (2), (3), (4) and (5). The basic elastic-plastic flow stress Eq. (1) was converted to Eq. (2) to calculate the plastic strain rate $\varepsilon_{P}$, in which the initial yield stress $k$ and isotropic material hardening $R$ were introduced to represent the viscoplastic behaviour of the material at elevated temperatures. $R$ was expressed by Eq. (3) as a function of the normalised dislocation density $\bar{\rho}$, which was accumulated by the plastic flow, dynamic recovery and static recovery, resulting in a normalised range from 0 to 1, as shown in Eq. (4). The temperature-dependent parameters, such as $E, k, K, B, C$ and $n$, were determined by using Arrhenius equations, while other material constants were experimentally determined [23]. Therefore, the blank material, desired temperature and strain rate ranges were required to be provided in those two functional modules to acquire a particular material card.

$\sigma=E\left(\varepsilon_{T}-\varepsilon_{P}\right)$

Table 1 Material properties of the AA6082 and P20 tool steel

\begin{tabular}{llll}
\hline Properties & Unit & AA6082 & P20 \\
\hline Density & $10^{-3} \mathrm{~g} / \mathrm{mm}^{3}$ & 2.7 & 7.85 \\
Young's modulus at $20^{\circ} \mathrm{C}$ & $\mathrm{GPa}$ & 70.0 & 205 \\
Young's modulus at $500^{\circ} \mathrm{C}$ & $\mathrm{GPa}$ & 19.5 & - \\
Poisson's ratio & - & 0.3 & 0.285 \\
Volumetric heat capacity & $\mathrm{mJ} /\left(\mathrm{mm}^{3} \cdot \mathrm{K}\right)$ & 2.4 & 3.6 \\
Thermal conductivity & $\mathrm{mW} /(\mathrm{mm} \cdot \mathrm{K})$ & 170 & 31.5 \\
Thermal expansion coefficient & $10^{-6} \mathrm{~K}^{-1}$ & 24.0 & 12.8 \\
\hline
\end{tabular}

$\dot{\varepsilon}_{P}=\left(\frac{\sigma-R-k}{K}\right)^{n_{1}}$

$R=B \bar{\rho}^{0.5}$

$\dot{\bar{\rho}}=A(1-\bar{\rho}) \dot{\varepsilon}_{P}-C \bar{\rho}^{n_{2}}$

$\phi(T)=\phi_{0} \exp \left(Q_{\phi} / R_{g} T\right)$

\subsubsection{The IHTC and friction coefficient between AA6082 and P20}

The functional module, IHTC-Mate, was operated to predict the IHTC evolutions as a function of contact pressure between the AA6082 and graphite-lubricated P20, as shown in Fig. 4a. Driven by a mechanism-based IHTC model, the overall IHTC was a sum of the heat transfer across the air gap $h_{a}$, solid contact $h_{s}$ and lubricant layer $h_{l}$, as shown in Eq. (6). $h_{a}$ was a constant that is independent of the other influential factors, while $h_{s}$ was determined by the harmonic mean value of the thermal conductivity of the blank and tool $K_{s t}$, the root mean square value of the surface roughness of the blank and tool $R_{s t}$ and the pressure-dependent parameter $N_{P}$, as shown in Eq. (7). $N_{P}$ was expressed as an exponential function of the ratio of the applied contact pressure $P$ to the ultimate tensile strength of the blank $\sigma_{U}$, as shown in Eq. (8). When a lubricant was applied, as shown in Eq. (9), $h_{l}$ was determined by the harmonic mean value of the thermal conductivity of the blank, tool and lubricant $K_{s l t}$, the root mean square surface roughness $R_{s t}$ and the lubricant-dependent parameter $N_{\delta}$, which had an exponential relationship to the lubricant thickness $\delta_{l}$, as shown in Eq. (10). The temperature-dependent parameters, such as $\alpha$ and $\sigma_{U}$, were calculated by Arrhenius equations, while the material constants, such as $\lambda, \beta$ and $\gamma$, were experimentally determined [14]. Therefore, when the thermal conductivity of the blank, tool and lubricant, the surface roughness of the blank and tool and the applied forming temperature were assigned in the functional module, IHTC-Mate, the desired IHTC evolutions for the two processing windows were subsequently generated in the form of look-up tables or packages compatible to the FE software.

$h=h_{a}+h_{s}+h_{l}$

$h_{s}=\alpha \frac{K_{s t}}{R_{s t}} N_{P}$

$N_{P}=1-\exp \left(-\lambda \frac{P}{\sigma_{U}}\right)$

$h_{l}=\beta \frac{K_{s l t}}{R_{s t}} N_{\delta}$

$N_{\delta}=1-\exp \left(-\gamma \delta_{l}\right)$ 
(a)

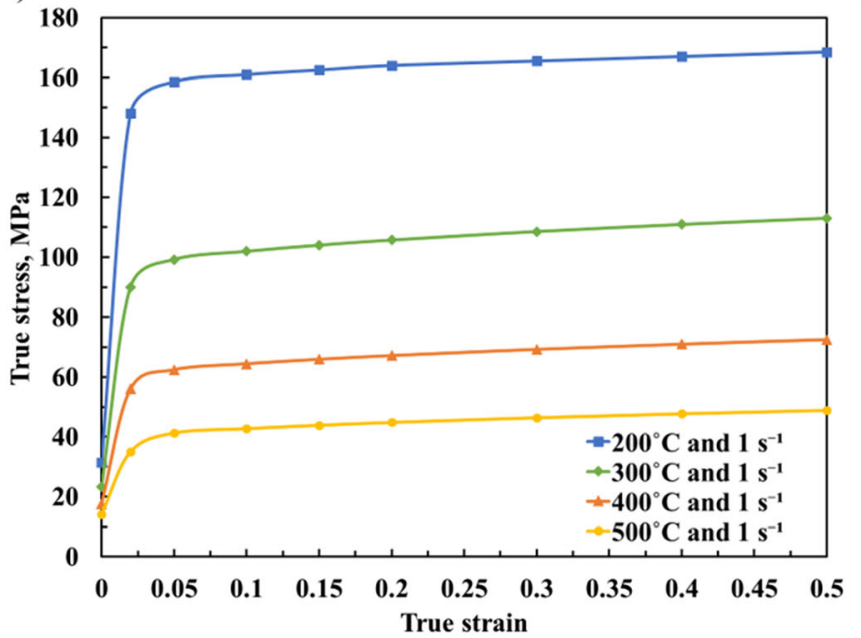

(b)

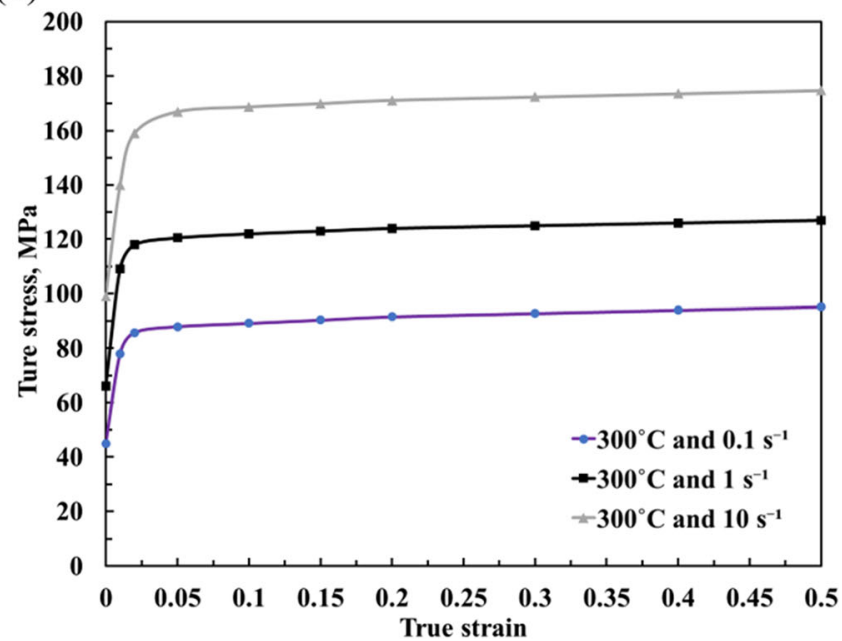

Fig. 3 Stress-strain curves of the AA6082 at a range of temperatures and strain rates

Another functional module driven by an interactive friction model [15], Tribo-Mate, was able to predict the evolutions of the friction coefficient as a function of the sliding distance between the AA6082 and graphite-lubricated P20 at different forming temperatures, accounting for lubricant breakdown, as shown in Fig. 4b. The overall friction coefficient was a sum of the lubricated-contact friction and dry-contact friction, as shown in Eq. (11). $\mu_{l}$ and $\mu_{d}$ were the temperature-dependent friction coefficients under the boundary-lubrication and dry-sliding conditions, respectively, expressed as Eq. (12). The interaction between $\mu_{l}$ and $\mu_{d}$ was determined by the lubricant fraction $\omega$, which was modelled as an exponential function of the lubricant thickness $\delta_{l}$, as shown in Eq. (13). The lubricant was diminished during sliding and its decreasing rate depended on the viscosity of the lubricant $\eta$, applied contact pressure $P$ and sliding speed $v$, as shown in Eq. (14). The material constants, such as $\theta, c$ and $m$, were experimentally determined in the previous study [15]. When the desired blank material, lubricant, forming temperature, contact pressure and sliding speed were provided in the functional module, Tribo-Mate, the evolution of the friction coefficient as a function of sliding distance could be generated in the form of look-up tables or packages compatible to the FE software. In addition, the average friction coefficient could also be calculated by Tribo-Mate for FE software that is not able to address the evolutionary friction.

$$
\begin{aligned}
& \mu=(1-\omega) \mu_{l}+\omega \mu_{d} \\
& \mu_{l, d}=\mu_{l, d 0} \exp \left(Q_{\mu} / R_{g} T\right) \\
& \omega=\exp \left[-\theta_{1} \delta_{l}(t)\right]^{\theta_{2}} \\
& \dot{\delta_{l}}=-\delta_{l}(0)\left(c P^{m_{1}} v^{m_{2}} / \eta^{m_{3}}\right)
\end{aligned}
$$

(a)

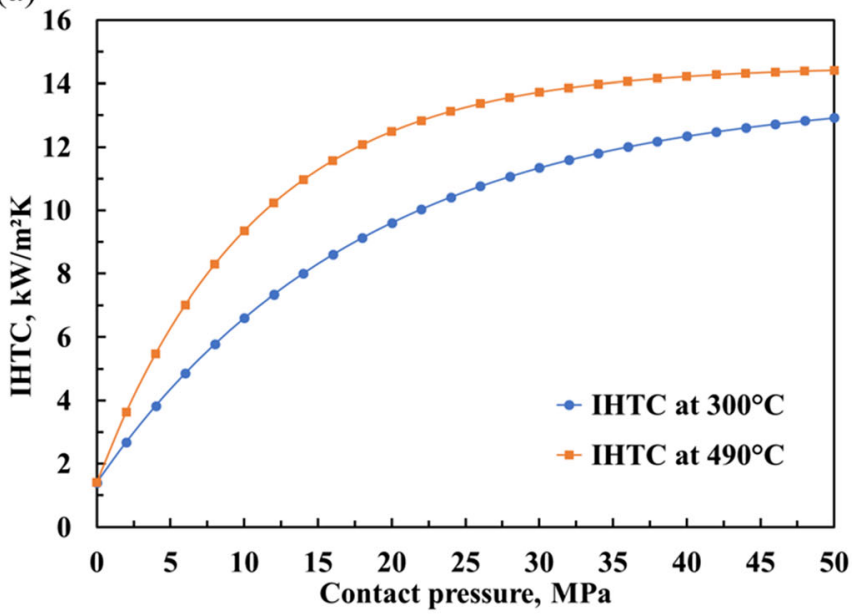

(b)

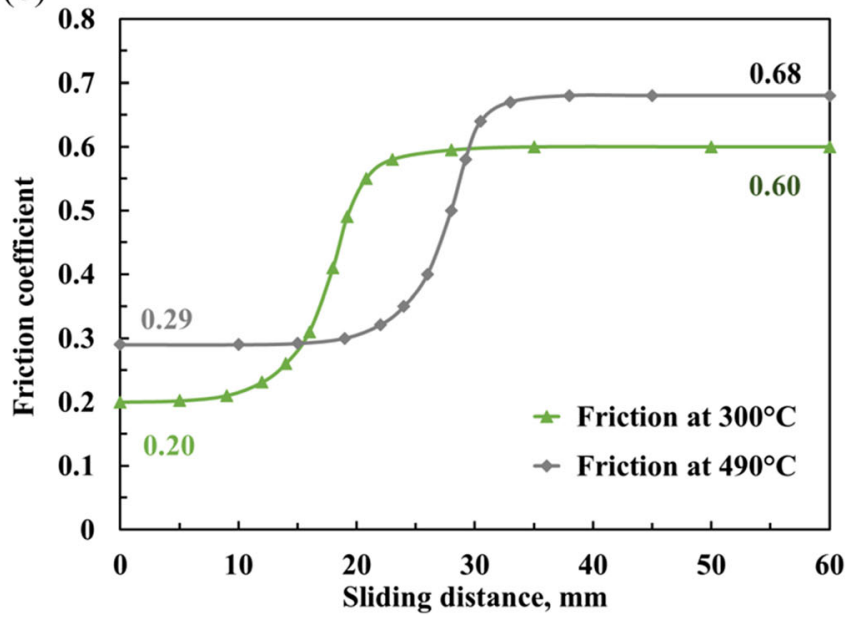

Fig. 4 a The IHTC evolutions as a function of contact pressure and $\mathbf{b}$ the friction coefficient evolutions as a function of sliding distance between the AA6082 and graphite-lubricated P20 for the hot stamping processes 


\subsection{FE simulation of hot stamping processes in AutoForm}

The FE simulations of hot stamping of a compact M-shaped panel component and a bulk door inner panel component were performed in the software AutoForm, as shown in Fig. 5. The material cards and boundary conditions generated by the functional modules of pre-FE modelling were implemented in both FE simulations. In the FE simulation of the M-shaped component, the blank and tools were meshed using triangular shell elements with a size of $2 \mathrm{~mm}$, which were kept constant throughout the simulation to facilitate the subsequent postFE evaluation process. The forming process consisted of three main stages. Firstly, a heating stage was defined to simulate the process of heating the blank to a target temperature, followed by a forming stage where the punch deformed the blank at the pre-defined forming speed. Finally, a quenching stage was defined whereby the punch was held against the deformed blank at a constant force to quench the formed component. In the FE simulation of the door inner component, the blank and tools were meshed using $5 \mathrm{~mm}$ triangular shell elements. In addition to heating, forming and quenching stages, a blankholding stage was defined to clamp the blank within the blankholder and die at a constant force before forming.

\subsection{Post-FE evaluation}

After the FE simulation, the simulated evolutionary thermomechanical characteristics of each element were exported and then uploaded in the developed platform to operate the functional modules of post-FE evaluation, thereby predicting the formability, quenching efficiency and postform strength of the formed components, as shown in Fig. 2.

\subsubsection{Formability of formed components}

The simulated major stress, minor stress, major strain and minor strain of each element at each time step were uploaded in the functional module, Formability, which applied the unified viscoplastic, Hosford and Marciniak-Kuczynski (MK) model to compute the failure criterion for each element, ranging from 1 to 10 [16]. The viscoplastic model was shown as Eqs. (1), (2), (3), (4) and (5), while the Hosford model was shown as Eq. (15) to represent the anisotropic material behaviour, computed by the major stress $\sigma_{11}$, minor stress $\sigma_{22}$, yield stress $\sigma$ and $R$ values in the longitudinal $R_{1}$ and transverse directions $R_{2}$. In the MK model, the propagation of a crack/ necking increased with increasing failure criterion, as shown in Eqs. (16), (17) and (18), where $\varepsilon_{2}$ was the minor strain and $f$ was the thickness ratio between the non-defect zone $a$ and defect zone $b$. The onset of localised necking occurred when the critical value, i.e., the increment of strain in the thickness direction $\varepsilon_{3}$, of 10 was reached, as shown in Eq. (19). When those required data were provided in formability, the failure criterion for all elements was distributed on the formed component and demonstrated by using a dedicated visualiser on the developed platform.

$$
\begin{aligned}
& R_{2} \sigma_{11 a, b}{ }^{l}+R_{1} \sigma_{22 a, b}{ }^{l}+R_{1} R_{2}\left(\sigma_{11 a, b}-\sigma_{22 a, b}\right)^{l} \\
& \quad=R_{2}\left(R_{1}+1\right) \bar{\sigma}_{a, b}{ }^{l} \\
& \varepsilon_{2 a}=\varepsilon_{2 b} \\
& \sigma_{11 a}=f \sigma_{11 b} \\
& f=f_{0} \exp \left(\varepsilon_{3 b}-\varepsilon_{3 a}\right) \\
& d \varepsilon_{3 b} / d \varepsilon_{3 a} \geq 10
\end{aligned}
$$
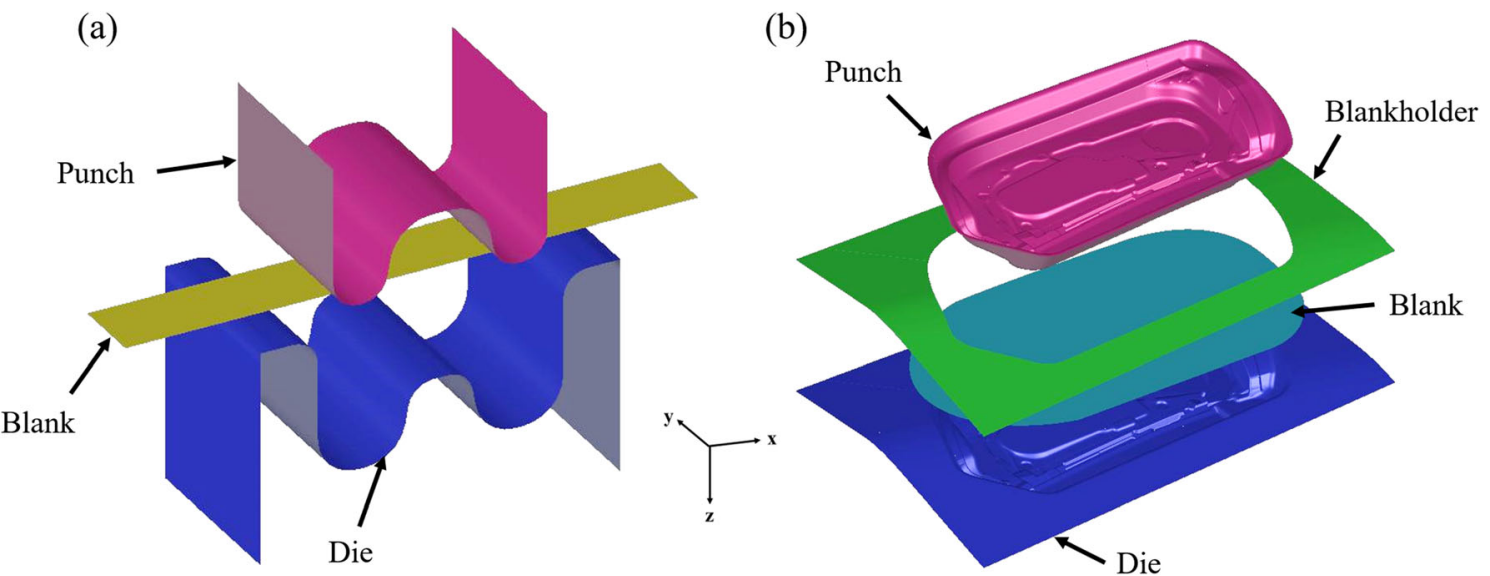

Fig. 5 The FE models in AutoForm for hot stamping of a the compact M-shaped panel component and $\mathbf{b}$ the bulk door inner panel component 


\subsubsection{Quenching efficiency of formed components}

The simulated temperature evolution as a function of forming time for each element was uploaded in the functional module, Tool-Maker, which superimposed the uploaded curves onto the CCP diagram of AA6082 [24]. The critical quenching efficiency of an element was achieved when its temperature evolution did not intersect the CCP diagram, which was then defined as a safe element; otherwise, the element was insufficiently quenched and highlighted as a fail element. The distribution of quenching efficiency of the entire component was subsequently demonstrated by using the dedicated visualiser.

\subsubsection{Post-form strength of formed components}

In order to predict the evolution of the post-form strength of the formed component as a function of artificial ageing or other post-form heat treatment, the simulated major strain and minor strain of each element at each time step were required to be uploaded on the functional module, Tailor, driven by a post-form strength prediction model [7]. The post-form strength was a sum of the intrinsic strength $\sigma_{i}$, the dislocation hardening $\sigma_{d i s}$, the solid solute strength $\sigma_{s s}$ and the precipitation hardening $\sigma_{p p t}$, furthermore, which was determined by the strength of bypass precipitates $\sigma_{b y}$ and shearable precipitates $\sigma_{s h}$, as shown in Eq. (20). In addition to $\sigma_{i}$ being assumed as a constant and $\sigma_{d i s}$ being modelled by Eq. (3), $\sigma_{s s}, \sigma_{b y}$ and $\sigma_{s h}$ were expressed by Eqs. (21), (22) and (23), respectively, where $C_{t}$ was the transient solute concentration in the matrix, $f_{t}$ was instantaneous volume fraction of precipitates, $r$ was the average radius of the precipitates, and $C_{1,2,3}$ was the material constant. Due to the dependence of $C_{t}$ and $f_{t}$ on the temperature and period of the post-form heat treatment, the process window was also required by this functional module in addition to the major and minor strain. For instance, a 6-h artificial ageing was conducted at $180^{\circ} \mathrm{C}$ after the door inner forming, while a 40 -min paint bake cycle was conducted at $120^{\circ} \mathrm{C}$ after the $\mathrm{M}$-shape forming. After providing the required data in Tailor, the distribution of the post-form strength of the formed component during the whole heat treatment process was computed and visualised.

$$
\begin{aligned}
& \sigma_{y}=\sigma_{i}+\sigma_{d i s}+\sigma_{s s}+\sigma_{p p t}= \\
& \\
& +\frac{\sigma_{d i s}+\sigma_{s s}+\sigma_{i s h}}{\sigma_{b y}+\sigma_{s h}} \\
& \sigma_{s s}=C_{1} C_{t}^{2 / 3} \\
& \sigma_{b y}=C_{2} f_{t}^{1 / 2} r^{-1} \\
& \sigma_{s h}=C_{3} f_{t}^{1 / 2} r^{1 / 2}
\end{aligned}
$$

\section{Results and discussion}

\subsection{Prediction of the thickness distribution of formed components}

The thickness distributions of the two formed components were simulated by AutoForm. As shown in Fig. 6, the simulated thickness distribution of the compact M-shaped component ranging from 1.93 to $2.01 \mathrm{~mm}$ had a good agreement with the experimentally measured thickness with an error of less than $6 \%$, while the maximum thinning occurred on the side walls of the central bend. Figure 7 shows the simulated thickness distribution of the door inner component ranging from 1.40 to $2.20 \mathrm{~mm}$, predicting that thinning up to $30 \%$ occurred in several regions.

The measured thickness at multiple points of the door inner was compared with the simulated results, indicating that good agreement was achieved for the complex geometry with an error of less than $10 \%$. The simulated thickness results of both forming processes obtained from AutoForm verified the accuracy of the assigned material cards and boundary conditions to represent the complex nature of material flow behaviours and boundary thermomechanical loadings in the hot stamping processes.

\subsection{Prediction of the formability and optimisation of the initial blank shape}

The functional module, Formability, predicted the distributions of the failure criterion on the two components, which were visualised on the developed platform. The failure criterion remained below the critical value for hot stamping of the M-shaped component with a range of 1 to 6 , as shown in Fig. 8, which was verified by the forming trials since the components were successfully formed with no visible necking/cracking, as shown in Fig. 6b. However, the maximum failure criterion did not occur in the regions that experienced the maximum thinning. As mentioned, the formability was a combined result of the temperature, strain rate and loading path. The temperature and strain rate of the adjacent regions with the maximum failure criterion and thinning were similar, while the loading path of those two regions was uniaxial when drawing into the die cavity, followed by a transition to biaxiality when the central bend was stretched into the Mshape. The region with the maximum thinning was continuously stretched by a biaxial loading at the end of the forming process, while the region with the maximum failure criterion was at a plan loading, thus resulting in lower formability. Due to the different loading path, the region with the maximum failure criterion was therefore located on the side wall of the central bend, which was not consistent with the region at the maximum thinning on the central bend. 
(a)

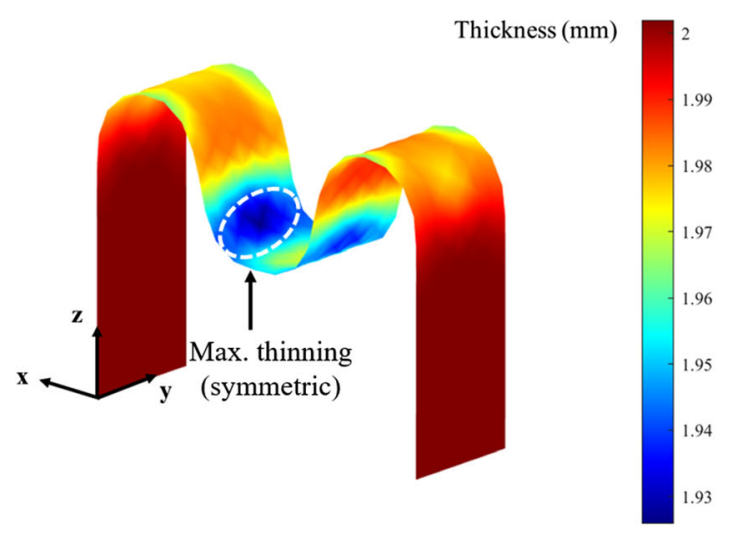

(b)

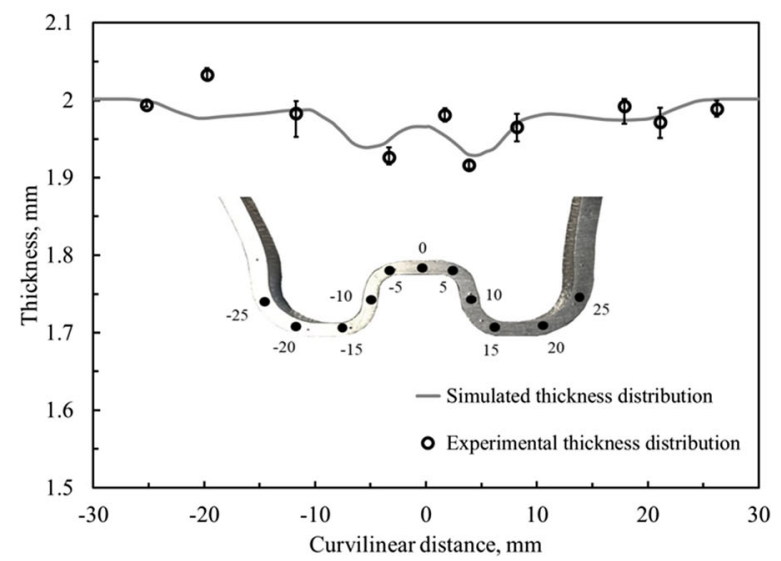

Fig. 6 a FE-simulated thickness distribution of the M-shaped component and $\mathbf{b}$ experimental and simulated thickness contour along the mid-section of the component

Figure 9 shows the distribution of the failure criterion of the door inner component, predicting that the cracks would occur near the corners of the deeper geometrical features (Regions A and D) that also experienced large thinning, which agreed with the forming trials. Although large thinning occurring, Regions B, C and E did not meet the critical failure criterion. On the contrary, high failure criterion was observed on Region $\mathrm{F}$ where thinning was marginal. Figure 10 shows the evolutions of the failure criterion, temperature, strain rate and loading path as a function of forming time on two typical regions $\mathrm{A}$ and B. The failure criterion for Region B remained marginal during the whole forming process, while it increased dramatically after the forming time of $0.4 \mathrm{~s}$ for region $\mathrm{A}$. It was found that the temperature of Region A was significantly lower than that of Region $\mathrm{B}$, and the strain rate of Region A was much higher than that of Region B after $0.4 \mathrm{~s}$, thereby leading to a higher failure criterion for
Region A. An uniaxial loading path was maintained on Region B, while it transited to a biaxial loading followed by another rapid transition to a plan loading on Region A after $0.4 \mathrm{~s}$, thus resulting in lower formability. Consequently, Region A had a much higher failure criterion than Region $\mathrm{B}$, although both regions experienced large thinning. The formability prediction of the two hot stamping processes indicated that the failure could not be simply evaluated by thickness/thinning distribution under the complex thermal and mechanical conditions. Instead, the combined effect of temperature, strain rate and loading path could contribute to an accurate prediction of the formability of the formed component.

The previous thinning and formability of the door inner component were predicted by using the initial blank shape after more than 20 iterations of optimisation, which minimised the cracking/necking and used in the forming trials. Figure 11 shows the formability results by using the
Fig. 7 Simulated thickness distribution of the door inner panel component and experimental measurement at the selected points

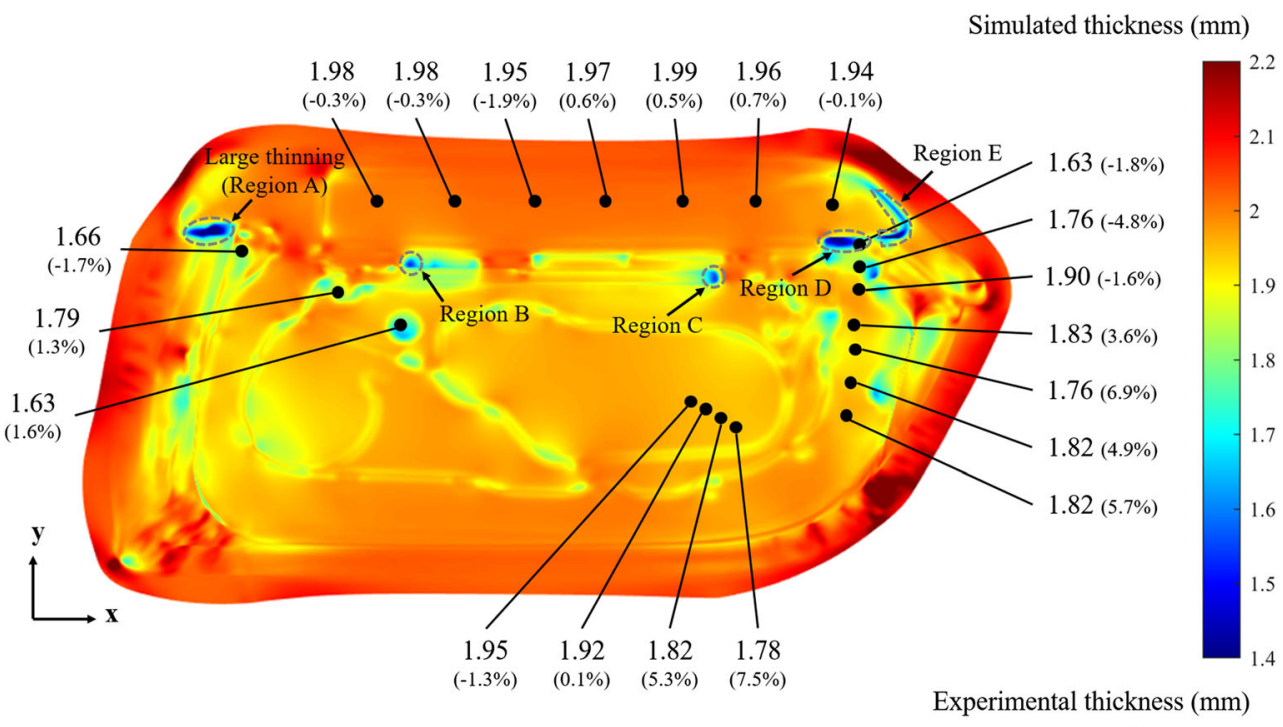




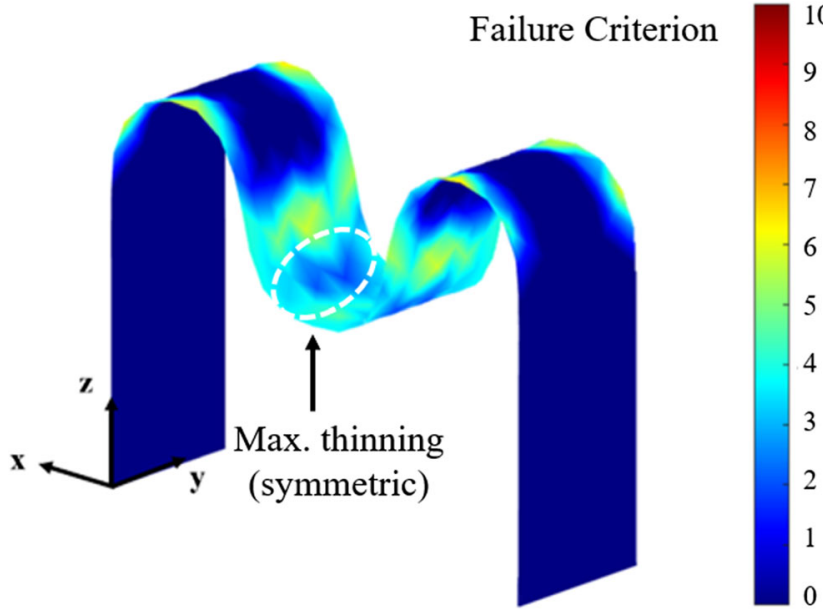

Fig. 8 Prediction of the formability of the M-shaped component

initial blank shape before optimisation. Severe cracking occurred along the top recess of the component as well as at the corners of the deeper geometrical features. The initial blank shape was subsequently optimised to improve the formability of the material based on the analysis of its evolutionary temperature, strain rate and loading path. The significant change in the failure criterion distribution emphasised the sensitivity of the initial blank shape in the hot stamping processes. The functional module, Formability, is therefore necessary to predict the failure of the formed component as a combined result of temperature, strain rate and loading path as well as optimise the initial blank shape.

Fig. 9 Prediction of the formability of the door inner component

\subsection{Prediction of the quenching efficiency of formed components}

The functional module, Tool-Maker, predicted the quenching efficiency of the two components respectively. Figure 12 a shows the comparison between the temperature evolutions of all elements on the M-shaped component and the CCP diagram of AA6082. As no intersection was found, the entire formed component was sufficiently quenched and then visualised on the platform, as shown in Fig. 12b. Figure 13 shows that the critical quenching efficient was also met for hot stamping of the door inner component. Consequently, secondary phases that consume alloying elements would not precipitate, and thus a high post-form strength would be obtained after a proper artificial ageing process (or post-form heat treatment). This also indicated that the applied tool material P20, the designed tool geometry, e.g. the die clarence, radius of fillet and angle of side walls, and the selected process windows, including the forming temperature, blankholding force and die-closing force, ensured the critical quenching efficiency to be met in the hot stamping processes. Therefore, the functional module, Tool-Maker, was able to optimise the tool design and process window by the prediction of the quenching efficiency.

\subsection{Prediction of the post-form strength of formed components}

The functional module, Tailor, predicted and visualised the distributions of the post-form strength/hardness of the two

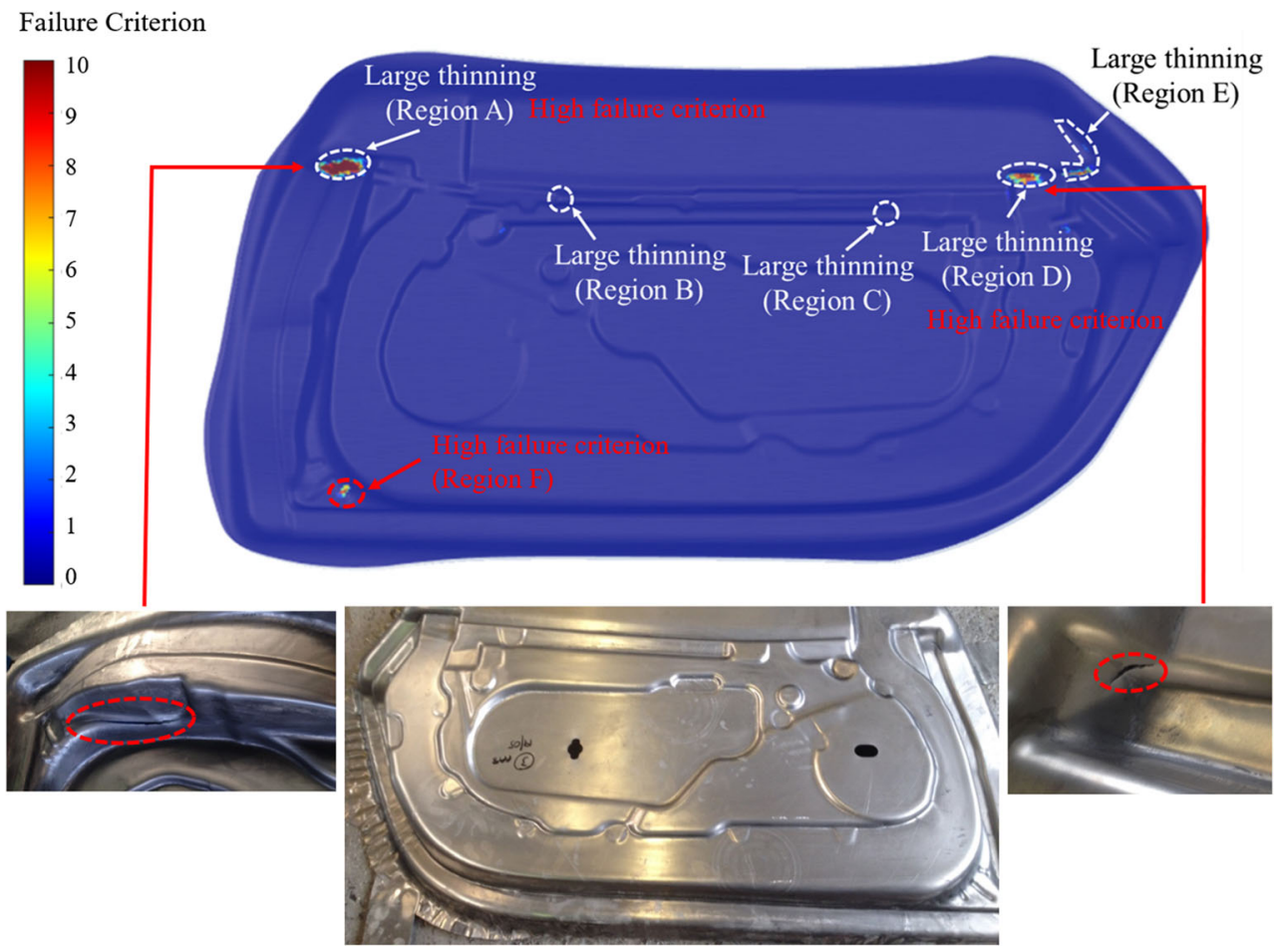


(a)

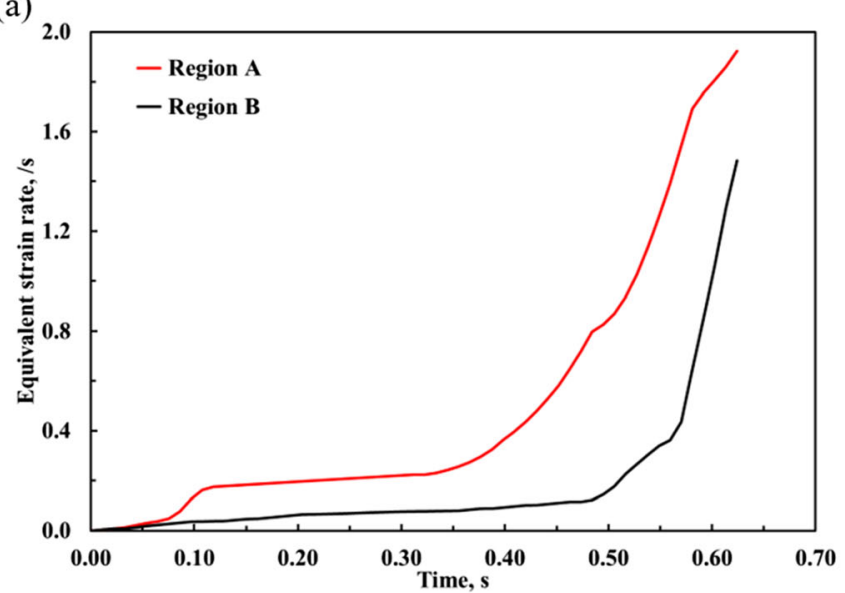

(c)

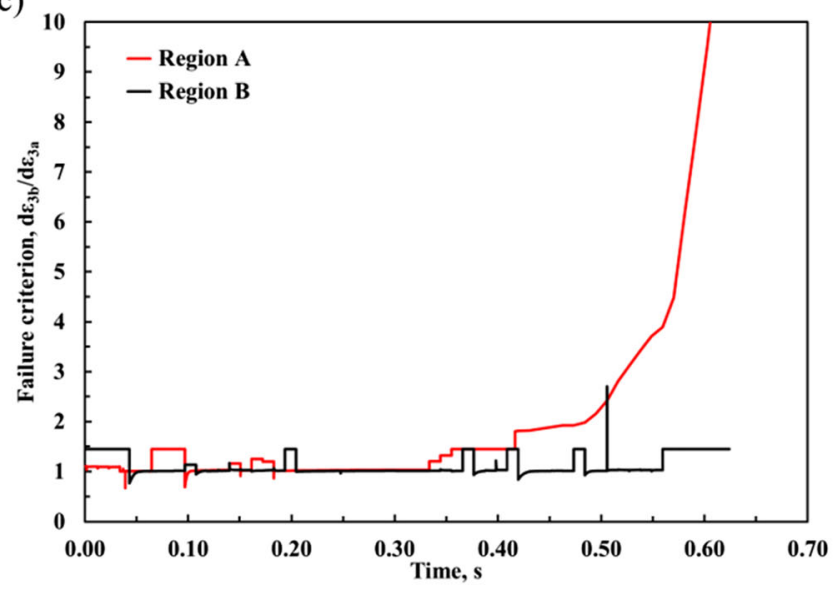

(b)

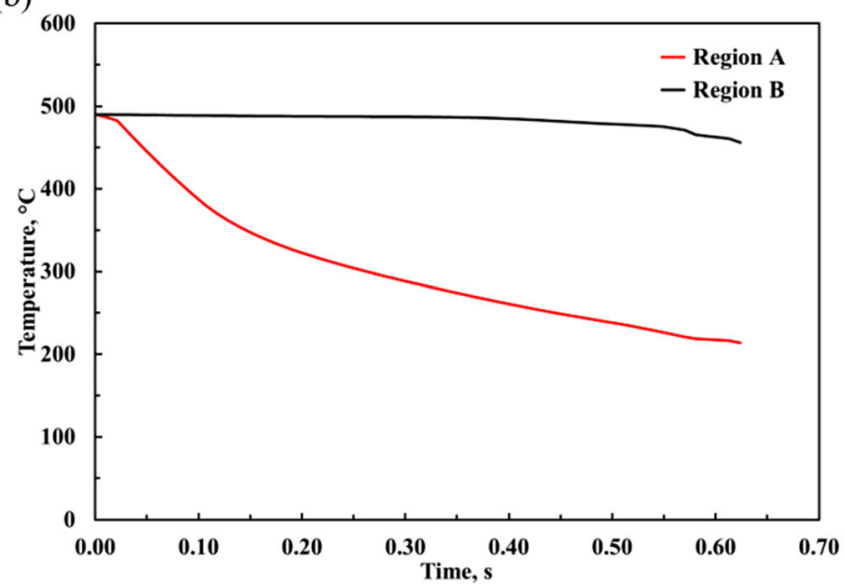

(d)

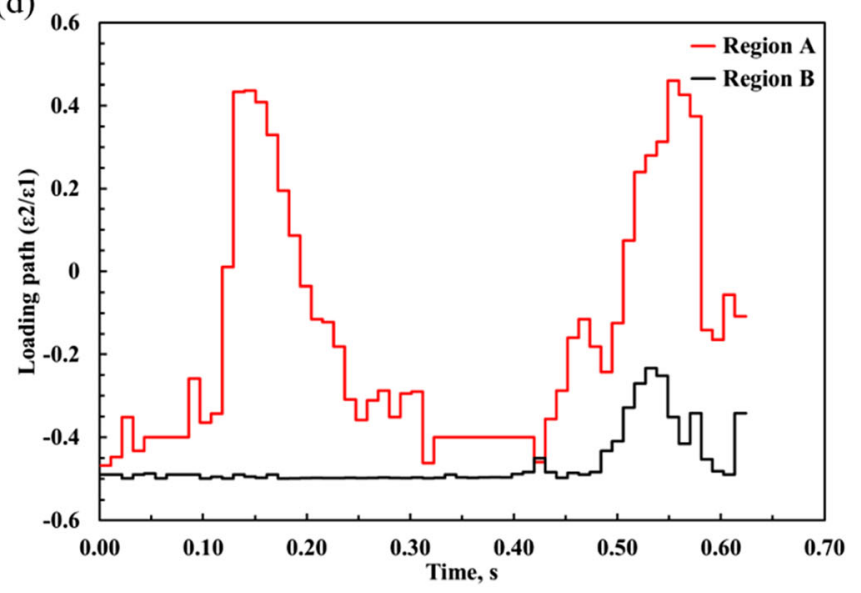

Fig. 10 The evolutions of a failure criterion, $\mathbf{b}$ temperature, $\mathbf{c}$ strain rate and $\mathbf{d}$ loading path as a function of forming time on Region A and B of the door inner component

formed components during the post-form heat treatment. As shown in Fig. 14, the average hardness of the M-shaped component was $84 \mathrm{HV}$ after quenching and increased in the subsequent paint bake cycle at $120{ }^{\circ} \mathrm{C}$, reaching $107 \mathrm{HV}$ after baking of $20 \mathrm{~min}$ and the peak value of $121 \mathrm{HV}$ after baking of $40 \mathrm{~min}$. The hardness of the M-shaped component was experimentally measured along its section contour after quenching and paint bake cycle of $40 \mathrm{~min}$, showing the average values of 86 and $120 \mathrm{HV}$, respectively. Figure 15 shows that the predicted post-form hardness of the door inner component was $88 \mathrm{HV}$ after quenching, $109 \mathrm{HV}$ after artificial ageing of $3 \mathrm{~h}$ at $180^{\circ} \mathrm{C}$ and $119 \mathrm{HV}$ after ageing of $6 \mathrm{~h}$ at $180^{\circ} \mathrm{C}$, reaching the peak hardness. Samples were cut from the flat bottom of the formed door inner component to conduct tensile tests, showing the yield strength of approximately $270 \mathrm{MPa}$ and the hardness of $111 \mathrm{HV}$. The error of the post-form hardness of the two components predicted by the functional module was less than $8 \%$.

The prediction of the post-form strength/hardness of the component mainly depended on the contributions of dislocation hardening, solid solution hardening and precipitation hardening. The contributions of dislocation hardening and solid solution hardening were closely tied to the normalised dislocation density, which was determined by the strain and strain rate experienced by the component. As the precipitates initiated and grew during the post-form heat treatment, the effect of precipitation hardening became the largest contributor to the increase in the hardness. Therefore, the post-form strength of the M-shaped component could be retained after short heat treatment due to a fine microstructure being obtained by using a rapid heating process. In contrast, the hot stamping of the door inner component had to be conducted at a higher temperature due to its more complex geometry and larger plastic deformation. Consequently, a longer artificial ageing process was required to recover the microstructure and thus post-form strength of the formed component. Hence, after post-processing the strain and temperature of the formed component, Tailor was able to predict the evolution of the post-form strength as a function of heat treatment, thereby computing the peak strength and optimising the process window of the post-form heat treatment/artificial ageing process. 
Fig. 11 a The initial blank shape for the door inner component before and after optimisation. $\mathbf{b}$ Prediction of the formability of the door inner component by using the initial blank shape before optimisation (a)

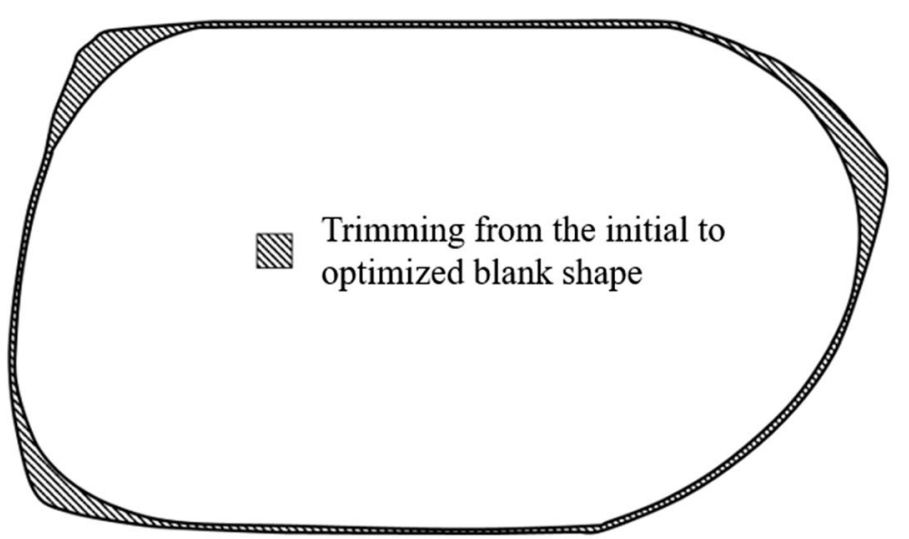

(b)

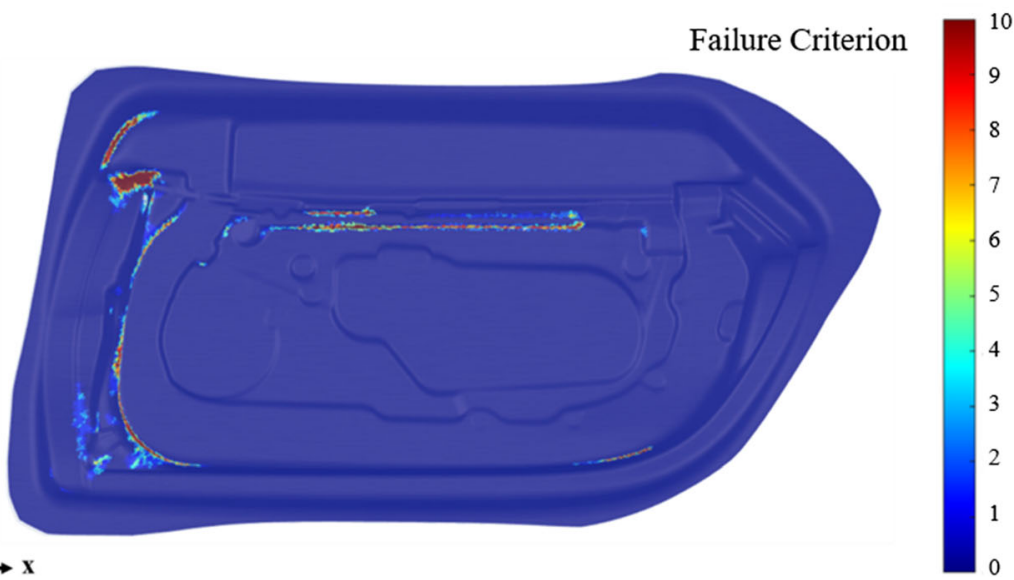

\section{Conclusion}

A software agnostic platform integrated by the model-driven functional modules was developed in the present research to provide cloud FEA of hot stamping of a compact M-shaped component and a bulk door inner component made from AA6082. According to the applied materials and process window, the flow stress, material properties, IHTC and friction coefficient could be generated by the functional modules named Flow Stress, Material Card, IHTC-Mate and TriboMate, respectively, in the form of compatible packages that fed into the desired FE software. Subsequently, the FE simulation of the hot stamping process was performed either locally or remotely on the developed platform. After uploading the simulated evolutionary thermomechanical characteristics of the formed component onto the platform, the functional (a)

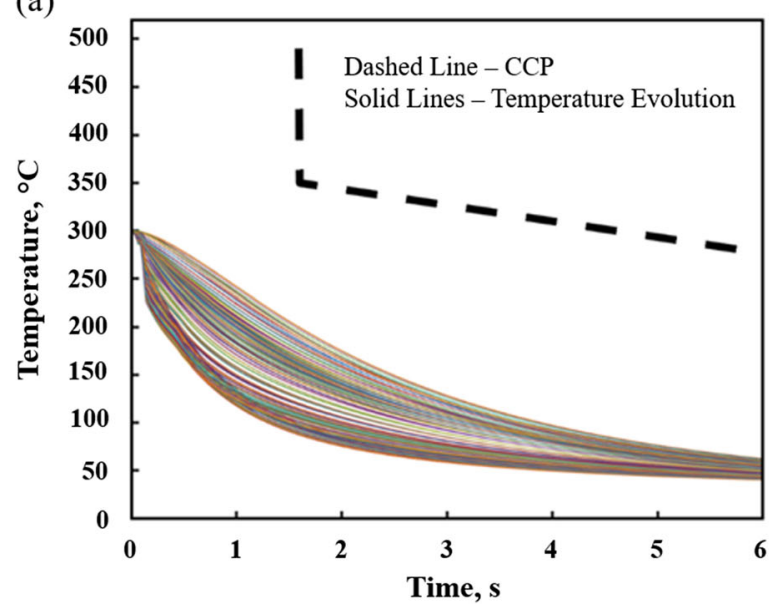

(b)

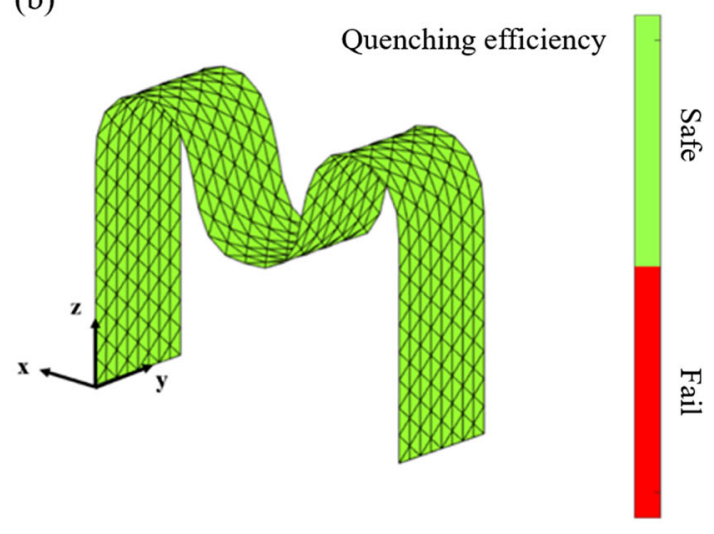

Fig. 12 a Comparison between the temperature evolutions of all the elements and CCP diagram and b visualisation of the quenching efficiency distribution for the M-shaped component 
(a)

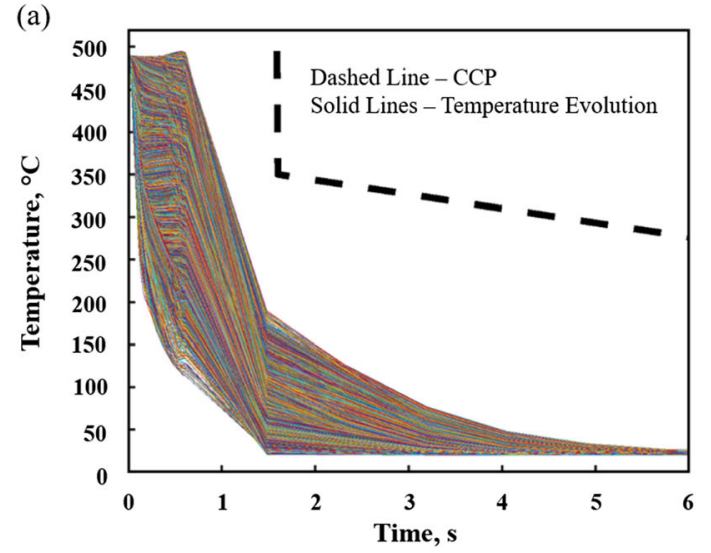

(b)

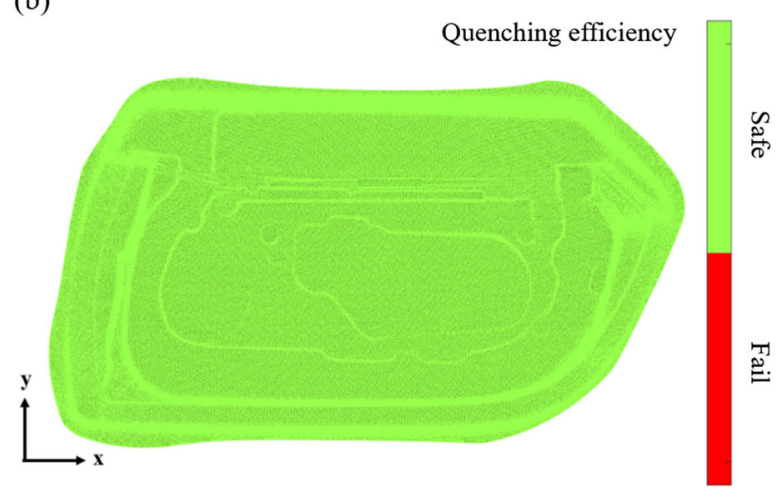

Fig. 13 a Comparison between the temperature evolutions of all the elements and CCP diagram and $\mathbf{b}$ visualisation of the quenching efficiency distribution for the door inner component

modules named Formability, Tool-Maker and Tailor could be operated to predict and demonstrate the distributions of the formability, quenching efficiency and post-form strength, respectively, on the dedicated visualiser, thereby optimising the

(a)



(c)

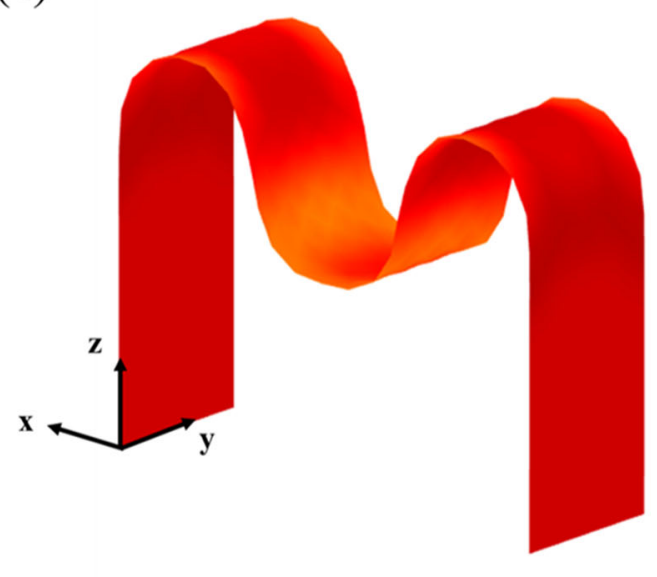

initial blank shape, tool design and process window. Good agreements between the cloud FEA and experimental results were found with an error of less than $10 \%$, verifying the accuracy of the developed platform. (b)

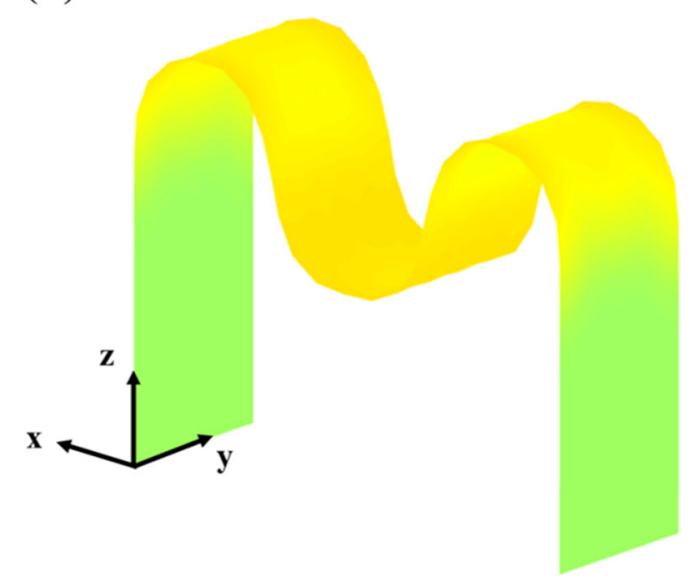

Hardness (HV)

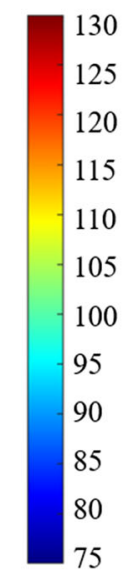

Fig. 14 Predicted post-form hardness distribution of the M-shaped component $\mathbf{a}$ after quenching, $\mathbf{b}$ after the paint bake of 20 min and $\mathbf{c}$ after the paint bake of $40 \mathrm{~min}$ 
(a)
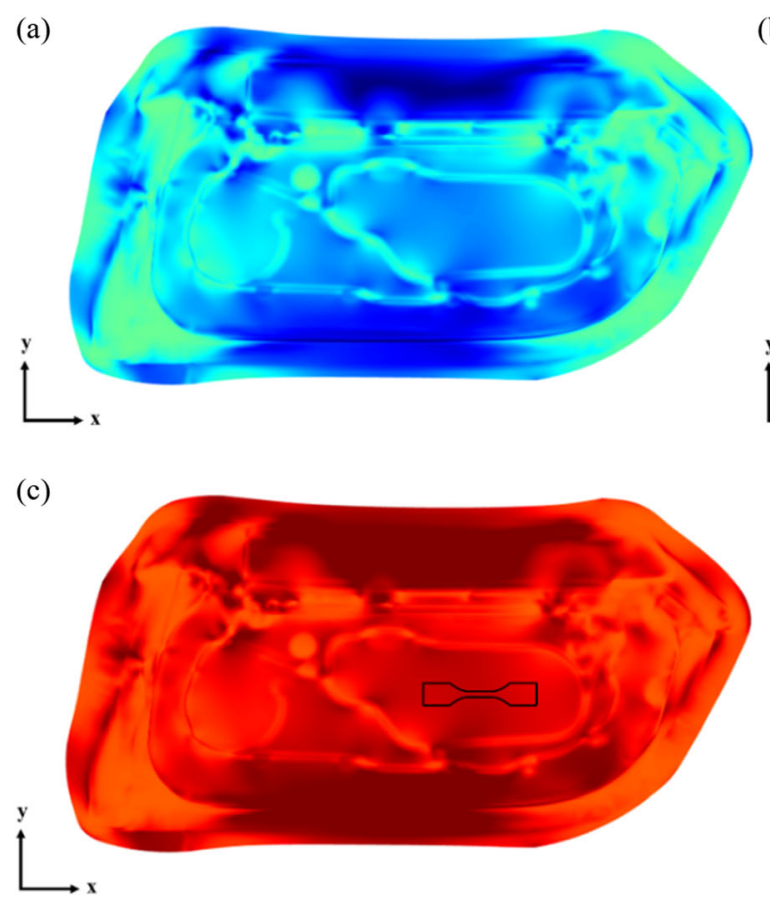

(b)

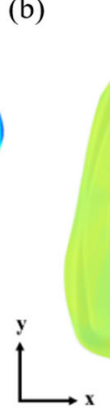

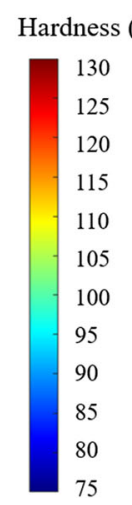

Fig. 15 Predicted post-form hardness distribution of the door inner component $\mathbf{a}$ after quenching, $\mathbf{b}$ after the artificial ageing of $3 \mathbf{h}$ and $\mathbf{c}$ after the artificial ageing of $6 \mathrm{~h}$

For the first time, the pre-FE modelling was combined with the cloud FEA to predict the material properties and boundary conditions with a particular processing window, resulting in excellent accuracy on the FEA. Meanwhile, the post-FE evaluation was also integrated to predict the formability, quenching efficiency and post-form strength, significantly expanding the functions of the conventional FEA. Furthermore, the mechanisms on the plastic deformation, material behaviour, boundary heat, mass transfer, etc. were explained by the developed functional modules driven by the experimentally verified models. Moreover, this platform is an open-source for various functional modules to be implemented to satisfy the desired demands. Therefore, it has a huge potential benefit on the hot stamping industry.

Authors' contributions Conceptualisation: M. Zhu, Y. Lim, J. Liu and X. LiuMethodology: Z. Cai, J. Liu and X. LiuSoftware: Y. Lim and D. SakshamValidation: Y. Lim and J. LiuWriting - original draft preparation: M. Zhu, Y. Lim and X. LiuWriting-review and editing: D. PolitisSupervision: X. Liu

Data availability The data and materials supporting the results of this article are included within the article.

\section{Compliance with ethical standards}

Competing interests The authors declare that they have no competing interest.

Ethical approval Not applicable.
Consent to participate Not applicable.

Consent to publish Not applicable.

Open Access This article is licensed under a Creative Commons Attribution 4.0 International License, which permits use, sharing, adaptation, distribution and reproduction in any medium or format, as long as you give appropriate credit to the original author(s) and the source, provide a link to the Creative Commons licence, and indicate if changes were made. The images or other third party material in this article are included in the article's Creative Commons licence, unless indicated otherwise in a credit line to the material. If material is not included in the article's Creative Commons licence and your intended use is not permitted by statutory regulation or exceeds the permitted use, you will need to obtain permission directly from the copyright holder. To view a copy of this licence, visit http://creativecommons.org/licenses/by/4.0/.

\section{References}

1. Merklein M, Wieland M, Lechner M, Bruschi S, Ghiotti A (2016) Hot stamping of boron steel sheets with tailored properties: a review. J Mater Process Technol 228:11-24. https://doi.org/10.1016/ j.jmatprotec.2015.09.023

2. Karbasian H, Tekkaya AE (2010) A review on hot stamping. J Mater Process Technol 210:2103-2118. https://doi.org/10.1016/j. jmatprotec.2010.07.019

3. Tekkaya AE (2000) State-of-the-art of simulation of sheet metal forming. J Mater Process Technol 103:14-22. https://doi.org/10. 1016/S0924-0136(00)00413-1

4. El Fakir O, Wang L, Balint D et al (2014) Experimental and numerical studies of the solution heat treatment, forming, and in-die 
quenching (HFQ) process on AA5754. Int J Mach Tools Manuf 87: 39-48. https://doi.org/10.1016/j.ijmachtools.2014.07.008

5. Zheng K, Dong Y, Zheng JH, Foster A, Lin J, Dong H, Dean TA (2019) The effect of hot form quench (HFQ ${ }^{\circledR}$ ) conditions on precipitation and mechanical properties of aluminium alloys. Mater Sci Eng A 761:138017. https://doi.org/10.1016/j.msea.2019.06.027

6. Lin J, Liu Y (2003) A set of unified constitutive equations for modelling microstructure evolution in hot deformation. J Mater Process Technol 143-144:281-285. https://doi.org/10.1016/ S0924-0136(03)00472-2

7. Zhang Q, Luan X, Dhawan S, Politis DJ, du Q, Fu MW, Wang K, Gharbi MM, Wang L (2019) Development of the post-form strength prediction model for a high-strength $6 \mathrm{xxx}$ aluminium alloy with pre-existing precipitates and residual dislocations. Int J Plast 119:230-248. https://doi.org/10.1016/j.ijplas.2019.03.013

8. Wang L, Sun Y, Ji K, et al (2017) Fast warm stamping of ultra-high strength steel sheets. Intellectual Property No.: 1713741.5

9. Sun Y, Wang K, Politis DJ, Chen G, Wang L (2020) An experimental investigation on the ductility and post-form strength of a martensitic steel in a novel warm stamping process. J Mater Process Tech 275:116387. https://doi.org/10.1016/j.jmatprotec. 2019.116387

10. Mori K, Abe Y, Miyazawa S (2020) Warm stamping of ultra-high strength steel sheets at comparatively low temperatures using rapid resistance heating. Int J Adv Manuf Technol 108:3885-3891. https://doi.org/10.1007/s00170-020-05642-x

11. Mori K, Maki S, Tanak Y (2005) Warm and hot stamping of ultra high tensile strength steel sheets using resistance heating. CIRP Ann - Manuf Technol 54:209-212. https://doi.org/10.1016/ S0007-8506(07)60085-7

12. Kopec M, Wang K, Politis DJ, Wang Y, Wang L, Lin J (2018) Formability and microstructure evolution mechanisms of Ti6Al4V alloy during a novel hot stamping process. Mater Sci Eng A 719:72-81. https://doi.org/10.1016/j.msea.2018.02.038

13. Garrett RP, Lin J, Dean TA (2005) An investigation of the effects of solution heat treatment on mechanical properties for AA 6xxx alloys: experimentation and modelling. Int J Plast 21:1640-1657. https://doi.org/10.1016/j.ijplas.2004.11.002

14. Liu X, El Fakir O, Meng L et al (2018) Effects of lubricant on the IHTC during the hot stamping of AA6082 aluminium alloy: experimental and modelling studies. J Mater Process Technol 255:175183. https://doi.org/10.1016/j.jmatprotec.2017.12.013
15. Hu Y, Zheng Y, Politis DJ, Masen MA, Cui J, Wang L (2019) Development of an interactive friction model to predict aluminum transfer in a pin-on-disc sliding system. Tribol Int 130:216-228. https://doi.org/10.1016/j.triboint.2018.08.034

16. Gao H, El Fakir O, Wang L et al (2017) Forming limit prediction for hot stamping processes featuring non-isothermal and complex loading conditions. Int J Mech Sci 131-132:792-810. https://doi. org/10.1016/j.ijmecsci.2017.07.043

17. Liu J, Wang A, Zheng Y, Liu X, Gandra J, Beamish K, Petre A, Wang LL (2017) Hot stamping of AA6082 tailor welded blanks for automotive applications. Procedia Eng 207:729-734. https://doi. org/10.1016/j.proeng.2017.10.820

18. Lin J, Dean TA (2005) Modelling of microstructure evolution in hot forming using unified constitutive equations. J Mater Process Technol 167:354-362. https://doi.org/10.1016/j.jmatprotec.2005. 06.026

19. Abedrabbo N, Pourboghrat F, Carsley J (2006) Forming of aluminum alloys at elevated temperatures - part 2: numerical modeling and experimental verification. Int J Plast 22:342-373. https://doi. org/10.1016/j.ijplas.2005.03.006

20. Li X, Roth CC, Mohr D (2019) Machine-learning based temperature- and rate-dependent plasticity model: application to analysis of fracture experiments on DP steel. Int J Plast 118:320 344. https://doi.org/10.1016/j.ijplas.2019.02.012

21. Wang A, El Fakir O, Liu J et al (2018) Multi-objective finite element simulations of a sheet metal-forming process via a cloudbased platform. Int J Adv Manuf Technol 100:2753-2765. https:// doi.org/10.1007/s00170-018-2877-x

22. Zhou D, Yuan X, Gao H, Wang A, Liu J, el Fakir O, Politis DJ, Wang L, Lin J (2016) Knowledge based cloud FE simulation of sheet metal forming processes. J Vis Exp 118:e53957. https://doi. org $/ 10.3791 / 53957$

23. Liu J, Wang A, Gao H, Gandra J, Beamish K, Zhan L, Wang LL (2018) Transition of failure mode in hot stamping of AA6082 tailor welded blanks. J Mater Process Technol 257:33-44. https://doi.org/ 10.1016/j.jmatprotec.2018.02.028

24. Milkereit B, Wanderka N, Schick C, Kessler O (2012) Continuous cooling precipitation diagrams of Al-Mg-Si alloys. Mater Sci Eng A 550:87-96. https://doi.org/10.1016/j.msea.2012.04.033

Publisher's note Springer Nature remains neutral with regard to jurisdictional claims in published maps and institutional affiliations. 